\title{
BASELINE WHITE SUCKER HEALTH AND REPRODUCTIVE ENDPOINTS FOR USE IN ASSESSMENT OF FURTHER DEVELOPMENT IN THE ALBERTA OIL SANDS
}

\author{
MARK E. MCMASTER, GERALD R. TETREAULT, THOMAS CLARK, JIM BENNETT, JESSIE \\ CUNNINGHAM, ERIN J. USSERY AND MARLENE EVANS \\ Environment and Climate Change Canada, Burlington, ON, Canada, Environment and Climate Change Canada, \\ Saskatoon, SK, Canada
}

\begin{abstract}
Adult fish health surveys are part of Canada's Environmental Effects Monitoring (EEM) programs for both metal mining and pulp and paper sectors under Canada's Fisheries Act. Similar protocols are used within the Joint Oil Sands Monitoring (JOSM) plan to develop baseline health for fish populations within the lower Athabasca River, Fort McMurray. Results reported here focus on the health of white sucker at five sites including upstream reference sites outside of the oil sands formation, a site within the formation upstream of oil sands industrial activity, and sites within the formation downstream of oil sands development. The objective here was to provide baseline data addressing questions regarding fish health based on site location. Additionally, an assessment of reproductive function (circulating steroid levels, secondary sex characteristics, gonad size and total fecundity) was conducted. To accumulate a strong baseline of fish health at the five sites, fish were collected for three consecutive years (20112013). Consistent changes in the health of white suckers within the formation itself were demonstrated with increased change documented downstream of oil sands development (2011-2012). Fish within the formation and downstream of oil sands development had increased condition factor and increased levels of internal fat stores relative to fish upstream of the oil sands area, changes confirmed in our 2012 collections. Ethoxyresorufin-O-deethylase activity in the liver was induced in fish within the formation with some increases downstream of oil sands development indicating increased exposure to inducing compounds, such as polycyclic aromatic compounds. Reproductive endpoints were not consistently altered in fish collected within the formation or downstream of oil sands development. Follow-up studies in 2013 identified potential improvements in fish health both within the formation and downstream of oil sands development. With a strong baseline of fish health presented here, the program will use critical effects sizes to monitor future fish health.
\end{abstract}

Keywords: environmental effects monitoring, EROD, fish health, growth, oil sands, reproduction and survival.

\section{INTRODUCTION}

The development of the fish program for the Joint Oil Sands Monitoring (JOSM) plan focused on fish health endpoints in select sentinel species as differences in growth, reproduction, condition and survival put fish at risk and is a reflection of the overall environment in which they live [1]. Understanding this level of risk allows for the management of the aquatic ecosystem, a required mandate under the Fisheries Act in Canada. Fish health is one pillar in the aquatic program and is supported by measurement of invertebrate biodiversity, water and sediment chemistry, toxicology and physical habitat measurements. The Environment Canada Integrated Monitoring Plan for the Oil Sands is summarized in [2], data for the program is available online [3] and a report on the integration of the water component is available [4] which evaluates whether ecological effects are occurring in response to oil sands developments. 
Although a large amount of historical fish information is available in the Oil Sands area, the use of methods employed in the Environmental Effects Monitoring (EEM) programs in Canada only began in the early 1990s. Some fish health information is available upstream and downstream of five pulp mills in the upper part of the Athabasca River [5], however the only fish health metrics for the Lower Athabasca River (LAR) began to be collected in the late 1990s through the Regional Aquatic Monitoring Program (RAMP 1997-2011) [6] and as part of specific research programs conducted through funding from the Program of Energy Research and Development (PERD) [7]. The JOSM fish health sampling program, where possible and practical, collected fish at similar sites to provide comparable data, although fish health sites were also selected to correspond to other components of the overall JOSM plan to help integrate the program [2].

Given the limited fish health data for the LAR, the JOSM program was designed to establish a strong baseline for fish health within the LAR for which comparisons could be made into the future following potential increased development in the area. It also served to evaluate reproductive health in the area to assess whether exposure to natural oil sands deposits influenced fish health and reproduction and to assess whether existing development within the area contributed to change in these parameters.

Fish health and reproductive studies on the mainstem Athabasca River consisted of sampling two sentinel fish species at sites upstream outside of the oil sands formation, sites within the formation upstream of development, and in the formation downstream of oil sands development (Fig. 1). The large-bodied white sucker (Catostomus commersoni) was sampled during the fall of each year as a sentinel species because sucker species are known to demonstrate high site fidelity outside their spring spawning migration [8]. Sucker species are benthic feeders and also provide potential linkages to the invertebrate community bioassessments [4]. A summary of response patterns in white sucker from these collections is presented in [9]; however, detailed data and reproductive assessments are presented here. Previous studies have also assessed fish health and reproductive function in the white sucker exposed to pulp mill effluent [10] with recovery being demonstrated following a number of process and treatment upgrades [11] and food limitation issues following closure of a mill [12]. Arens et al. [13] have also used the white sucker in the oil sands area to evaluate population level impacts. A second sentinel fish species, the trout perch (Percopsis omiscomaycus), was included in the JOSM studies as a small bodied fish with reduced mobility and is presented in [14]. The first three years of results from the white sucker health assessments are discussed here including reproductive assessments.

\subsection{Objectives}

This 3-year JOSM study used methods developed for Canada's EEM programs to evaluate fish health in sentinel species collected within the LAR $[5,15]$. Three years of data were collected in order to obtain a strong baseline of fish health at all sites and to help understand variability in fish health endpoints. Similar to the EEM programs, each year of data is used to assess change in fish health between sites. The first year is to demonstrate change, the second year of data collection is used to confirm responses demonstrated in year one. In the EEM program, the third year of data collection would be to evaluate the magnitude and extent of these confirmed changes $[5,15]$, it is used here to help understand reference site variability in the EEM endpoints. The JOSM fish health studies were designed to evaluate the potential for development in the oil sands area to affect overall fish health and reproductive endpoints using the sentinel species approach. 


\section{METHODS}

\subsection{Study design}

The study design for the JOSM fish health work was to collect 20 adult male and 20 adult female white sucker at each of the five sites, to measure select EEM fish health endpoints $[5,15]$. Study sites were selected in order to collect reference fish upstream, outside of the Athabasca oil sands formation, within the Athabasca formation upstream of oil sands development, and within the Athabasca formation downstream of oil sands development (Fig. 1).

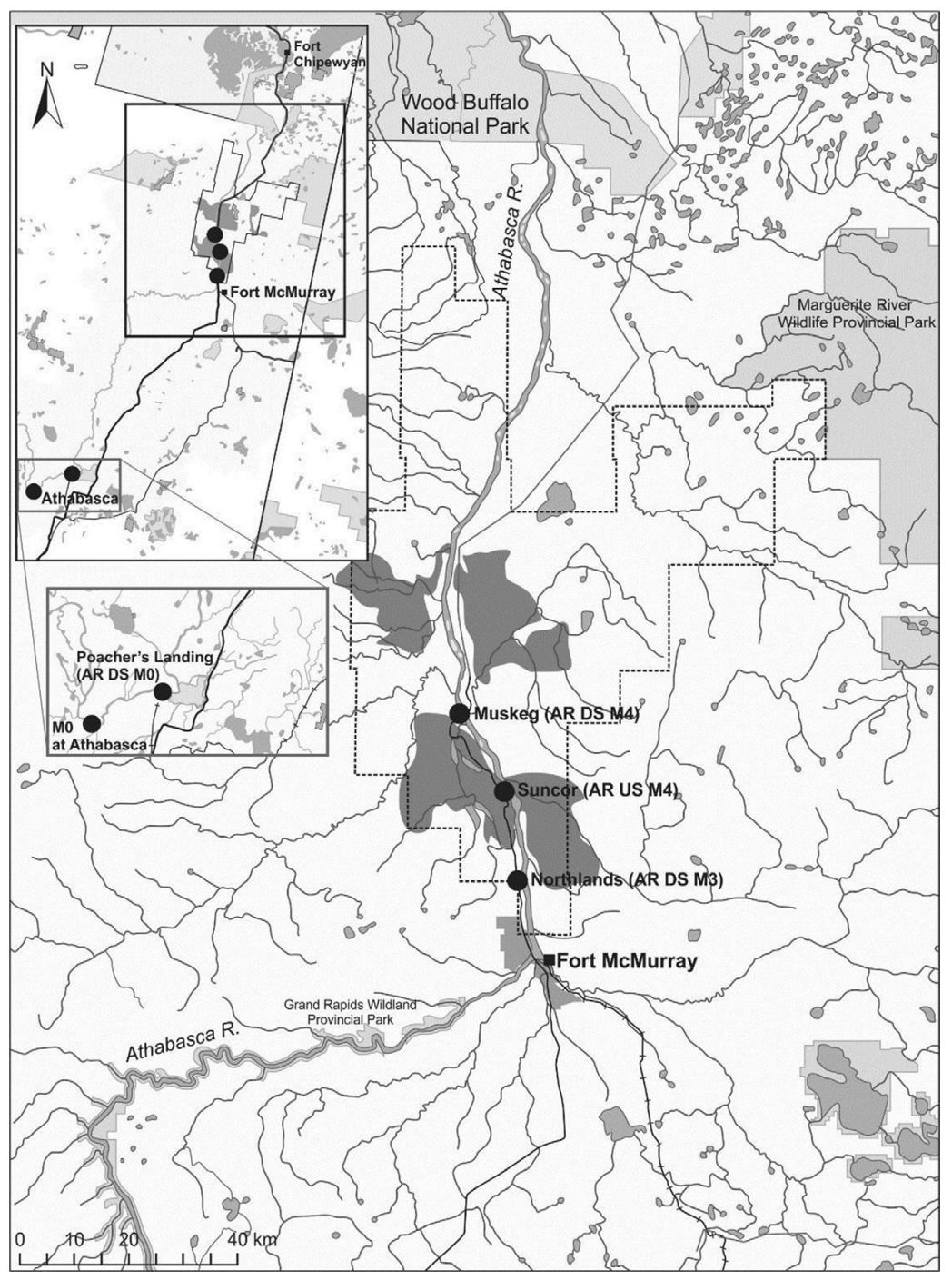

Figure 1: Map of fish collection sites, two sites outside of the oil sands formation, one site in the formation upstream of development and two sites in the formation downstream of oil sands development. 
Fish health would then be compared to reference fish for change due to both the formation and oil sands development. Three years of data were collected at each location to establish variability in EEM endpoints and used to obtain baseline data for assessment of further development within site and to develop predictive relationships of fish health in response to increased development in the area.

\subsection{Sampling sites and fish health endpoints}

On the Athabasca River, white sucker were sampled as the large bodied sentinel species. Collection sites (Fig. 1), included two sites outside of the Athabasca oil sands formation (M0 - Athabasca (only in 2012 and 2013) and AR DS M0 - Poacher's Landing), one site within the formation upstream of oil sands development (AR DS M3 - Northlands) and two sites within the formation and within the oil sands development area (AR US M4 - Suncor and AR DS M4 - Muskeg). Sampling was conducted in the months of September-October for three straight years (2011-2013). Boat electrofishing was used to collect white sucker for fish health, reproductive assessments and for contaminant analysis at all sites. Removal of stunned fish was accomplished using dip nets (approx. 0.5-cm mesh size) followed by transportation to the on-site laboratory for processing. Detailed fish health assessments of individual fish included assessment of age, growth, condition, liver size and gonad size relative to body weight, and abnormalities assessments, all EEM endpoints used in the monitoring plans $[5,15]$. As an indicator of exposure to PACs, hepatic mixed-function oxygenase (MFO) activity was measured using ethoxyresorufin-O-deethylase (EROD) methods of Van Den Heuvel et al. [16]. Muscle and liver tissue were collected for contaminant (PACs and alkylated PACs) analyses [14]. White sucker were also rated on visceral lipid stores using a subjective fat index ranging from 1 to 5 adapted from Munkittrick and Dixon [17]. Reproductive assessments included the EEM endpoints of gonadosomatic index (GSI) as well as supporting total fecundity estimates $[5,15]$. In addition, circulating plasma levels of reproductive hormones (17 $\beta$-estradiol and testosterone in females and 11-ketotestosterone and testosterone in males) were measured to support reproductive assessments [18]. A subjective assessment of the expression of secondary sexual characteristics was also conducted using a scale of $0-5$ for tubercle expression [10].

\subsection{Statistical methods}

Within year comparisons: Statistical analyses were conducted according to guidance documents prepared for the EEM programs for pulp and paper and metal mining [5, 15]. ANOVA was used to compare the fish health endpoints of weight, length and fecundity of fish among sites following checks for homogeneity of variances and normality of the data. ANCOVA was used to compare fish health endpoints of condition of the fish (length versus body weight relationships - weight/length ${ }^{3} \times 100$ ), gonadosomatic indices (gonad weight versus body weight relationships - gonad weight/body weight $\times 100$ ), liver somatic indices (liver weight versus body weight relationships - liver weight/body weight $\times 100$ ) and fecundity (number of eggs versus body weight and length) among sites with pairwise comparisons used to identify site differences when they existed. Non-parametric Kruskal-Wallis analysis was used to compare MFO activity, circulating steroid levels, expression of secondary sexual characteristics (tubercles), internal fat stores and the age of fish among sites.

Comparisons between years: EEM programs are cyclical in design. The first year of data collection is generally one upstream reference location and one downstream effluent exposed 
site. Comparison of fish health endpoints between sites are made and an evaluation of fish response patterns to the effluent are conducted $[1,17]$. In the next sampling period (generally every 3 years in EEM but the following year in this case), the objective is to confirm responses seen in the previous year of sampling $[5,15]$. As three years of data were collected in this study, response patterns were compared among the three years of collections (20112013) and assessments made as to whether the changes found were the same, getting better or getting worse. Through years of data collection from the EEM programs for pulp and paper and metal mining, critical effect sizes (CES) have been developed and were applied here for decision endpoints and for assessing natural background variability [5, 15]. Accepted CES for condition are 10\%, while 25\% CESs are used for all other EEM endpoints with changes above or below the CES requiring further assessment [5, 15]. For white sucker, average of the means for the upstream reference sites over time were calculated, magnitudes of difference calculated and CES used to assess change at downstream sites. All raw data can be found at [3] and summary tables of data are presented in McMaster et al. [9].

\section{RESULTS}

\subsection{1 - Fish health and evaluating site differences}

In 2011, white sucker were collected from four sites on the Athabasca River (Fig. 1 - site M0 was not sampled in 2011). Male white sucker captured within the deposit were older, longer, heavier and had increased condition (with magnitude of differences exceeding the 10\% CES) relative to the reference white sucker captured outside of the formation $(p<0.05$, Table 1$)$. These fish also had increased internal fat stores in the body cavity around the intestines and liver $(p<0.05)$. Male white sucker downstream of development also grew faster with increased length and weight at any given age relative to upstream reference males [14]. Male gonad size was not different between sites $(p>0.05)$, and expression of secondary sexual characteristics were also similar (Table 1). Interestingly, circulating levels of 11-ketotestosterone were higher in males collected within the formation downstream of oil sands development while testosterone levels were similar between sites (Table 2). Male white sucker within the formation had increased hepatic MFO activity using EROD methods relative to the upstream reference site $(p<0.001$, Table 3 ), with no significant differences among sites within the formation and downstream of oil sands development.

In 2011, female white sucker collected at all three sites within the formation had increased condition factor (with magnitude of differences exceeding CES) and levels of internal fat around the intestines and liver relative to upstream reference females $(p<0.05$, Table 4$)$. Female white sucker at the furthest oil sands development downstream site (AR DS M4) were also longer, heavier and had increased growth rates [14], and invested more energy into reproductive development $(p<0.05$, Table 4$)$. Female white sucker total fecundity estimates were different between sites $(p<0.05)$. AR DS M4 females had more eggs than females from the other three sites (Table 4). When expressed relative to the weight or length of the fish however, there were no site differences in the fecundity of the females $(p>0.05)$ [14]. Although $17 \beta$-estradiol levels appeared lower in females collected within the formation downstream of oil sands development at the furthest downstream site, variability was high and no significant site differences existed (Table 2). Circulating testosterone levels were also similar in females from all sites. Female white sucker in 2011 demonstrated more of a graded MFO induction, with AR DS M0 being lowest, induced at AR DS M3 in the formation, highest at the AR US M4 site, and reduced somewhat at the AR DS M4 location $(p<0.05$, Table 3$)$. 


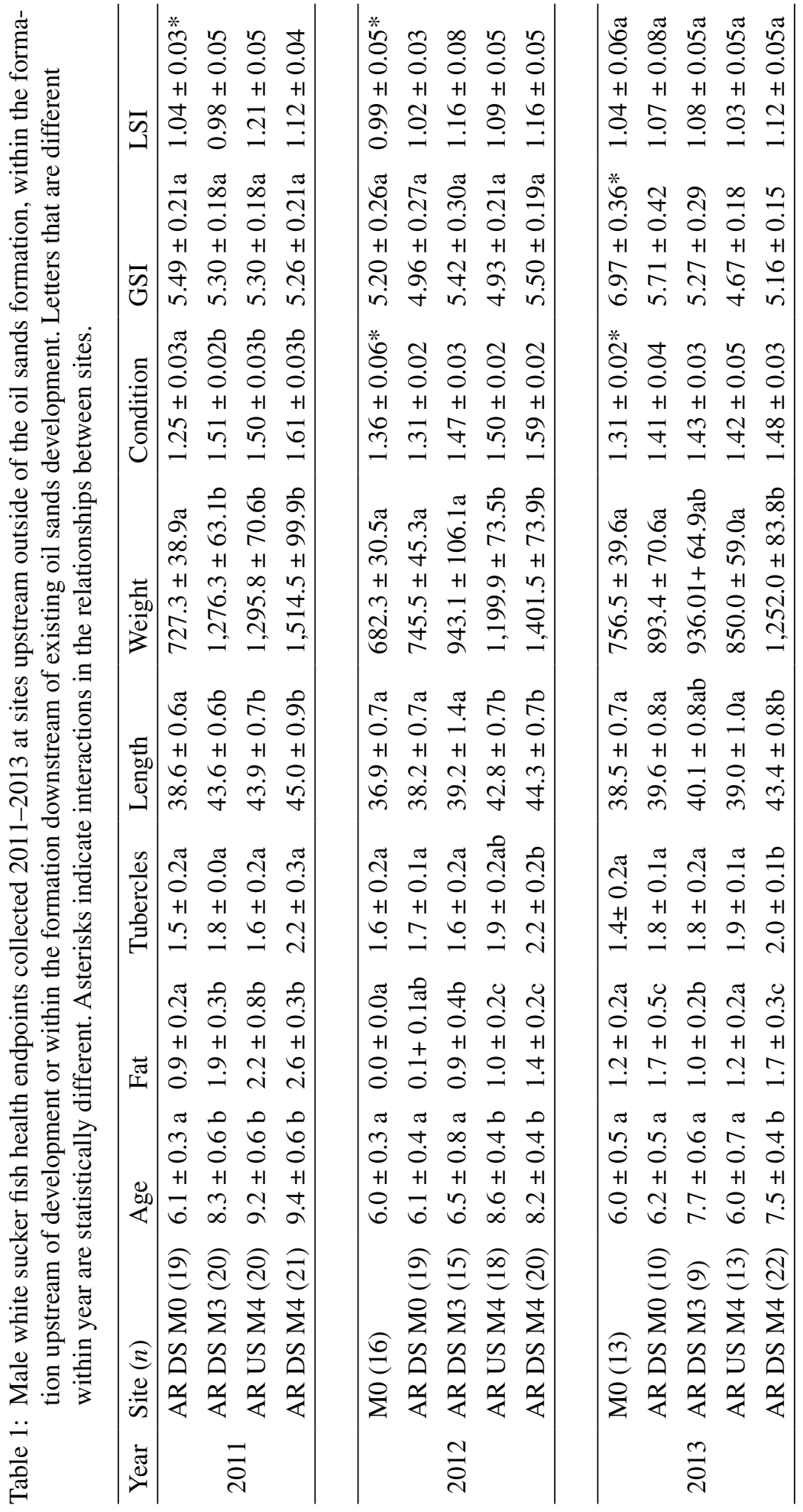




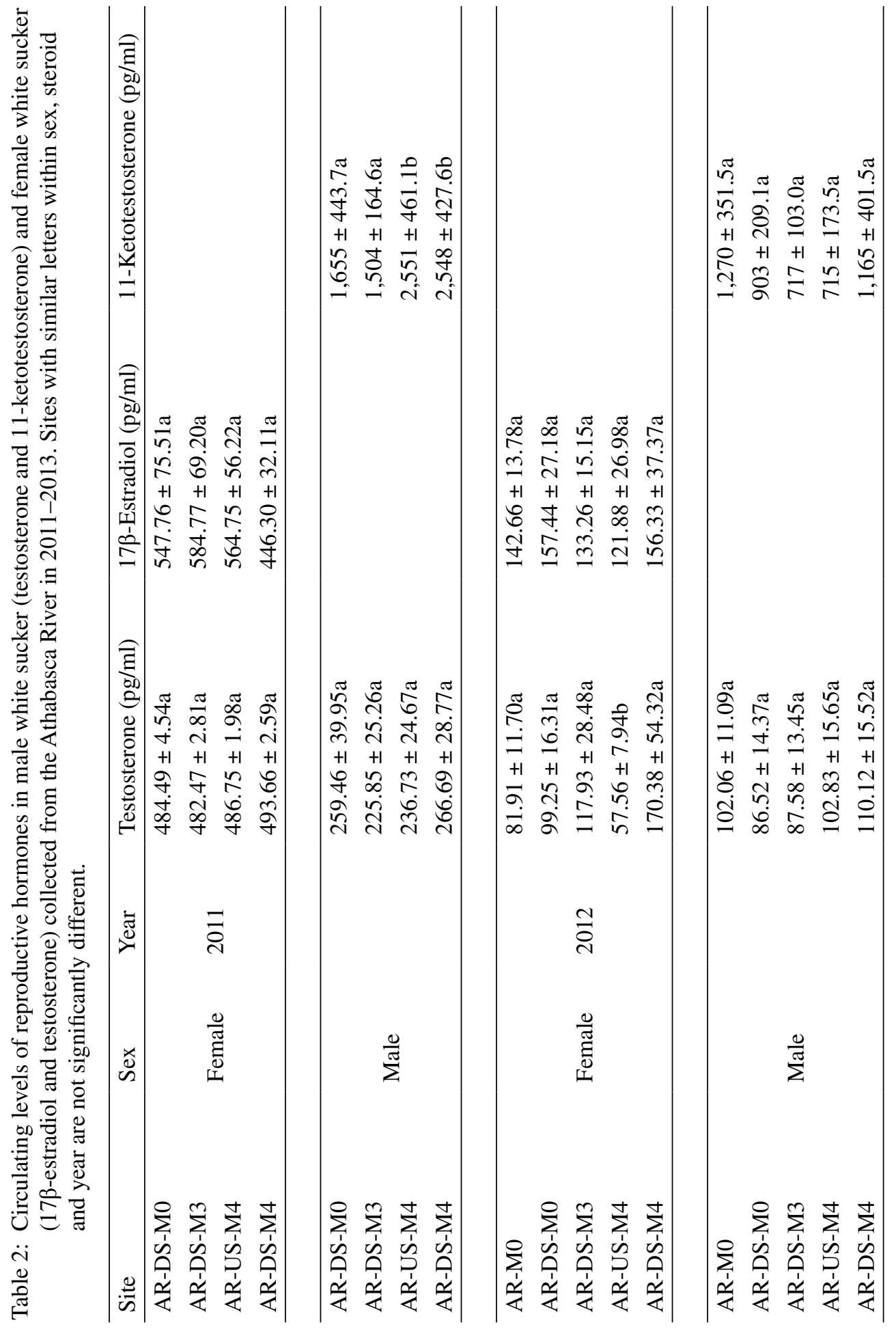




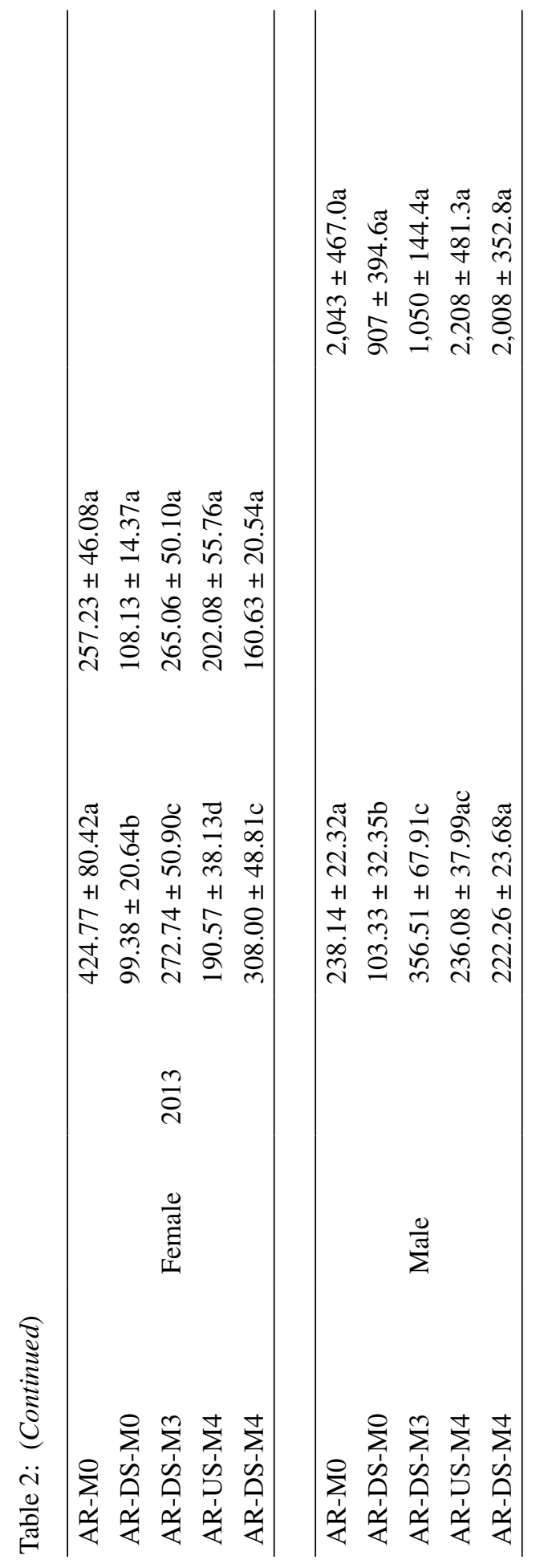


Table 3: Ethoxyresorufin-O-deethylase (EROD) activity in male and female white sucker liver samples collected from sites on the Athabasca River during 2011-2013. Values represent the means \pm S.E. with similar letters within a year and sex not significantly different.

\begin{tabular}{|c|c|c|c|}
\hline Sex & Year & Location & EROD $(\mathrm{pmol} / \mathrm{min} / \mathrm{mg})$ \\
\hline \multirow{14}{*}{ Male } & \multirow{4}{*}{2011} & AR DS M0 & $1.61 \pm 0.17 \mathrm{a}$ \\
\hline & & AR DS M3 & $7.14 \pm 0.74 b$ \\
\hline & & AR US M4 & $10.42 \pm 2.12 b$ \\
\hline & & AR DS M4 & $8.02 \pm 1.24 b$ \\
\hline & \multirow{5}{*}{2012} & M0 & $1.62 \pm 0.18 \mathrm{a}$ \\
\hline & & AR DS M0 & $1.55 \pm 0.14 \mathrm{a}$ \\
\hline & & AR DS M3 & $8.09 \pm 1.25 b$ \\
\hline & & AR US M4 & $8.16 \pm 1.17 b$ \\
\hline & & AR DS M4 & $9.03 \pm 1.52 b$ \\
\hline & \multirow{5}{*}{2013} & M0 & $2.28 \pm 0.34 \mathrm{ac}$ \\
\hline & & AR DS M0 & $1.36 \pm 0.25 \mathrm{a}$ \\
\hline & & AR DS M3 & $6.67 \pm 1.61 \mathrm{bc}$ \\
\hline & & AR US M4 & $13.11 \pm 3.18 b$ \\
\hline & & AR DS M4 & $11.01 \pm 2.25 \mathrm{~b}$ \\
\hline \multirow{14}{*}{ Female } & \multirow{4}{*}{2011} & AR DS M0 & $0.75 \pm 0.05 \mathrm{a}$ \\
\hline & & AR DS M3 & $2.19 \pm 0.30 \mathrm{~b}$ \\
\hline & & AR US M4 & $4.66 \pm 0.93 b$ \\
\hline & & AR DS M4 & $3.15 \pm 0.32 b$ \\
\hline & \multirow{5}{*}{2012} & M0 & $0.89 \pm 0.09 \mathrm{a}$ \\
\hline & & AR DS M0 & $0.87 \pm 0.08 \mathrm{ac}$ \\
\hline & & AR DS M3 & $4.45 \pm 1.58 b$ \\
\hline & & AR US M4 & $6.34 \pm 1.56 b$ \\
\hline & & AR DS M4 & $2.48 \pm 0.40 \mathrm{bc}$ \\
\hline & \multirow{5}{*}{2013} & M0 & $0.72 \pm 0.06 \mathrm{a}$ \\
\hline & & AR DS M0 & $0.59 \pm 0.05 \mathrm{a}$ \\
\hline & & AR DS M3 & $2.84 \pm 0.38 b$ \\
\hline & & AR US M4 & $5.29 \pm 1.28 b$ \\
\hline & & AR DS M4 & $4.80 \pm 1.19 b$ \\
\hline
\end{tabular}




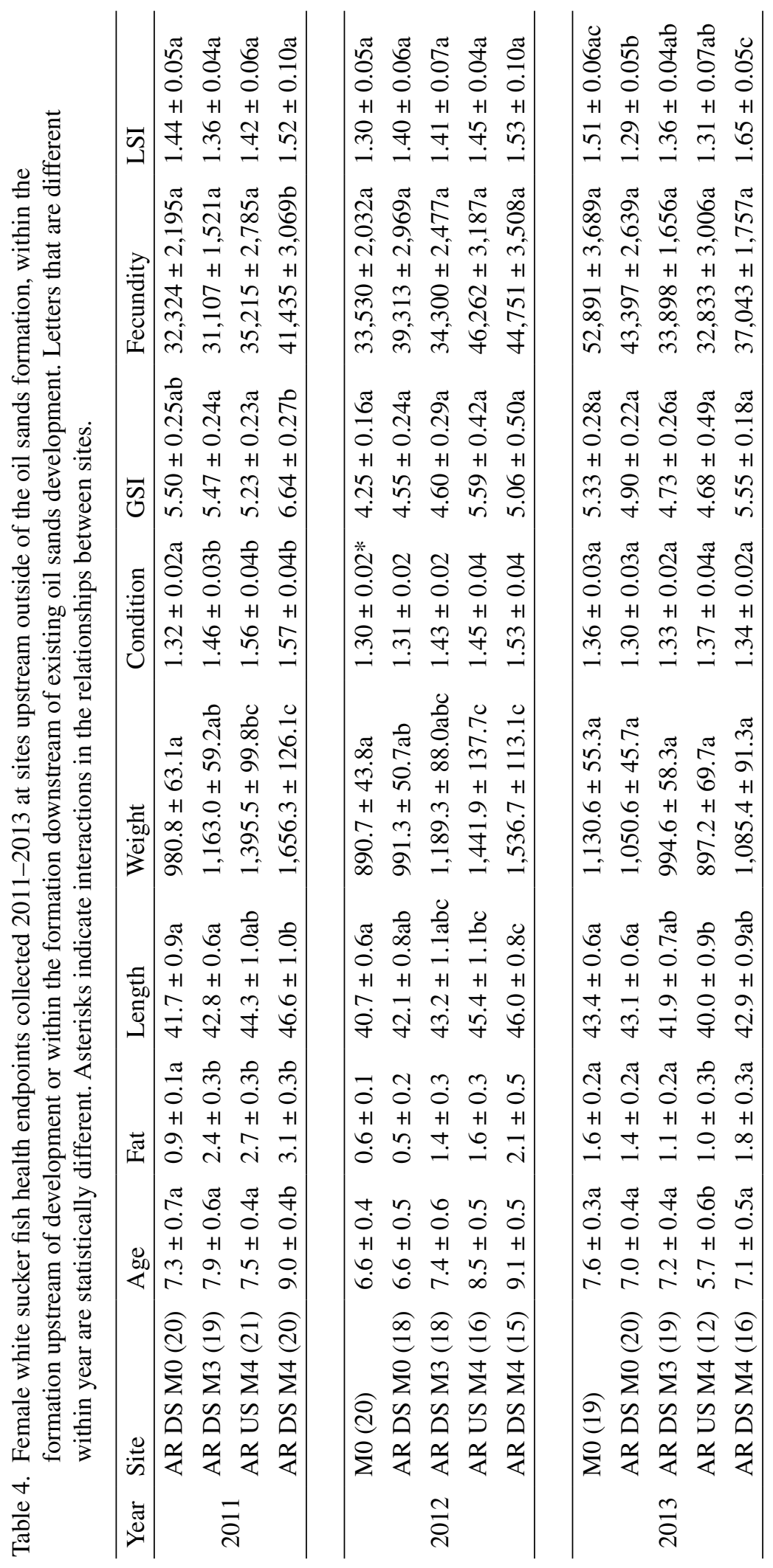




\subsection{2 - Fish health and confirmation of responses}

In 2012, an additional reference location (M0 Athabasca) was added for fish health within the JOSM program (Fig. 1) upstream of Poacher's Landing. This site was used for water quality in the JOSM program and is upstream of the municipal wastewater discharge for the town of Athabasca. It serves as the upper most reference site for white sucker health as well as a reference location to evaluate the potential influence pulp mill discharge has on fish health at the AR DS M0 location. All male fish EEM endpoints were similar between the two upstream locations outside of the formation in 2012 so were pooled for comparison. Male white sucker downstream of oil sands development were older, longer and heavier than reference fish, with increased internal fat stores and increased condition with magnitude of differences exceeding the CES ( $p<0.05$, Table 1). In 2012, the formation site AR DS M3, was somewhat intermediate in most of the male white sucker health endpoints. Similar to the white sucker collections in 2011, the major response pattern was one of nutrient enrichment as fish downstream of oil sands development were longer, heavier and had increased condition and internal fat stores $(p<0.05)$. Male investment into reproductive development did not differ between sites similar to 2011; however, expression of secondary sexual characteristics were increased within the formation downstream of oil sands development with highest expression at the furthest downstream site $(p<0.05)$. 11-Ketotestosterone levels were quite variable in male fish in 2012, with no site differences although levels were higher at the furthest downstream site where tubercles were more pronounced (Table 2). No site differences in circulating testosterone levels were evident. EROD activity was similar to that in 2011 as male white sucker within the formation were induced relative to upstream reference males $(p<0.05)$ with no differences from those collected in the formation to those collected downstream of oil sands development (Table 3).

In 2012, similar to male white sucker, all fish EEM health endpoints were comparable between the two upstream locations for female white sucker. Female white sucker were older at the downstream locations within the formation relative to both reference sites and generally longer, heavier and with increased condition similar to 2011, although only significant at the furthest downstream oil sands development site (AR DS M4) $(p<0.05$, Table 4). Magnitude of site differences relative to the overall reference site average only exceeded the $10 \%$ CES at the AR DS M4 location. No significant differences in female white sucker growth [14] or internal fat were found, although trends to increased internal fat were evident downstream of oil sands development $(p>0.05)$. Female investment of energy into reproductive development appeared to be higher in females collected in the formation downstream of oil sands development, but was not significantly greater than upstream reference sites (Table 4). Total fecundity numbers mirror that of GSI, with more eggs in females collected within the formation downstream of oil sands development; however, no significant statistical differences were present. No significant differences in circulating $17 \beta$-estradiol were found in female fish; however, females collected within the formation downstream of oil sands development (AR US M4) had reduced circulating levels of testosterone $(p<0.05$, Table 2$)$. Female EROD activity was increased in all three locations within the formation with no differences downstream of oil sands development $(p<0.05$, Table 3$)$.

\subsection{3 - Fish health, are changes at sites the same, getting better or getting worse?}

Fishing was more difficult in 2013 with sample sizes especially for males lower than the previous 2 years of collections. Generally, in 2013, male white sucker collected within the formation were comparable to upstream reference fish. Male white sucker collected at the furthest 
downstream oil sands development site, AR DS M4 were often significantly different than the M0 upstream reference site. However, these fish were not different than those collected downstream of the pulp mill discharge outside of the formation at the AR DS M0 site (Table 1). No significant difference was calculated in the condition of male fish, however this may have been due to lower numbers of fish captured/sampled at four of the five sites in 2013 (see Table 1 for $n$ at each site). The calculated power to detect a $10 \%$ difference in condition with $\alpha$ of 0.05 was $76 \%$ and differences in condition in year 1 were $>20 \%$ and $<5 \%$ in year 3 so it is not a power issue. There was an interaction in the relationship between gonad weight and body weight for male white sucker with unusually high gonad weights relative to all years in males collected at the furthest upstream reference site M0. Expression of secondary sex characteristics again were higher in males collected at the furthest downstream oil sands development site but just slightly and steroid levels were variable with no site differences in 11-ketotestosterone $(p>0.05)$. Testosterone levels were lowest in males collected downstream of the pulp mill discharge (AR DS M0) and males at the site within the formation upstream of oil sands development having higher testosterone levels (Table 2). Male white sucker EROD activity was still induced at all sites within the formation $(p<0.001)$ similar to the two previous years (Table 3 ).

Generally, in 2013, female white sucker collected within the formation were also similar to upstream reference fish. Female white sucker were generally more similar in all EEM health endpoints, although liver size did differ significantly between sites, no formation or oil sands development relationship was evident $(p<0.05$, Table 4$)$. Female fish from AR US M4 were generally younger, shorter and had less internal fat, however sample sizes were low and these responses were opposite to what was found in 2011 and 2012. Similar to males, no significant difference was seen in the condition of female suckers between sites. The calculated power to detect a $10 \%$ difference in condition with $\alpha$ of 0.05 was greater than $76 \%$ indicating power was not the issue. Female investment of energy into reproductive development showed no site differences and total number of eggs in the gonad did not differ although were quite variable, with power calculated to be greater than $65 \%$ to detect a $25 \%$ difference in GSI. Female white sucker from the Athabasca M0 location had by far the largest number of eggs across years with a significantly different relationship between length and number of eggs relative to the other sites in $2013(p<0.05)$ [14]. Circulating levels of $17 \beta$-estradiol were variable and not significantly different between sites however, circulating levels of testosterone were most different between the two upstream reference locations outside of the formation (Table 2). Similar to males in 2013, female white sucker collected downstream of the pulp mill discharge had the lowest circulating levels of both steroids. EROD activity was induced in female white sucker collected within the formation $(p<0.05)$ with no differences in induction between the AR DS M3 site upstream of oil sands development and the two sites downstream of oil sands development (Table 3).

\subsection{Natural background variability in reproductive development}

With 3 years of data (five collections from two upstream reference locations), it was possible to assess reference site variability in reproductive development and to develop baselines for reference sites to compare differences in downstream fish to overall natural variability. Using the reference data, the mean male and female white sucker gonadosomatic indices at the upstream reference sites were determined and then upper and lower limits set using the CES of 25\% determined through the EEM programs [5, 15]. In 2011, male gonadal development was very uniform over the four sites sampled (Fig. 2). In 2012, variability between sites increased somewhat, although all sites were well within $25 \%$ of the reference site means for gonadal development (Fig. 2). In 2013 however, male gonadal development was significantly 


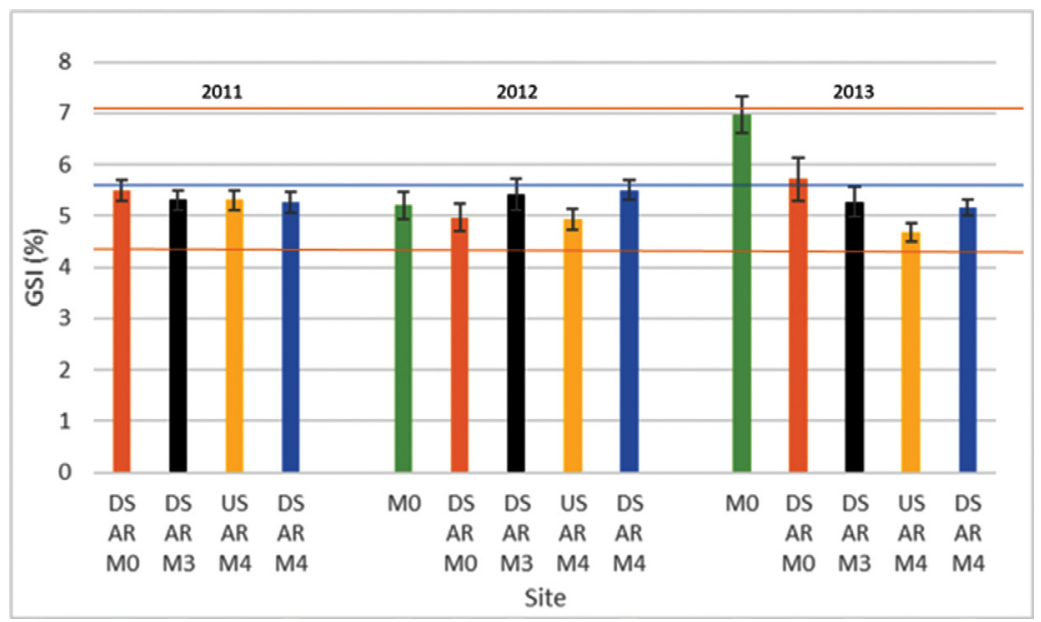

Figure 2: Male white sucker gonadosomatic indices collected in 2011-2013 with the mean reference site GSI (blue line) \pm the $25 \%$ critical effect size (red lines).

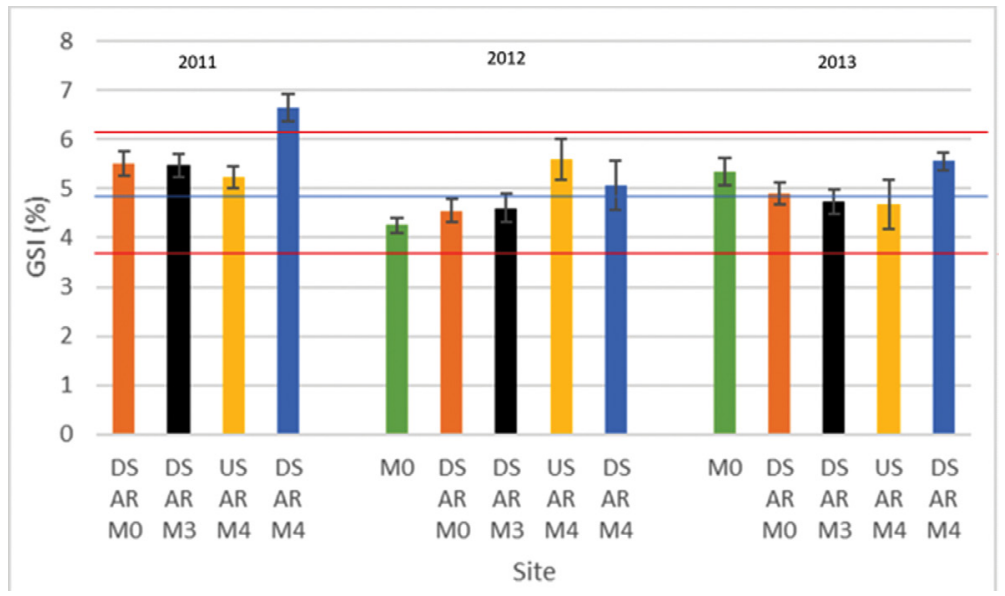

Figure 3: Female white sucker gonadosomatic indices collected in 2011-2013 with the mean reference site GSI (blue line) \pm the $25 \%$ critical effect size (red lines).

higher at the furthest upstream reference location (M0), approaching the $25 \%$ reference site mean and higher than any site in the three years of collections. This large reference GSI in 2013 also influenced the overall reference site mean and upper and lower limits. One of the downstream oil sands development sites (US AR M4) was reduced somewhat and was approaching the lower end of the reference 25\% CES in 2013.

Female white sucker gonadosomatic indices, the reference site means and the $25 \%$ CES are shown in Fig. 3. GSI in female white sucker collected in 2011 at the furthest downstream oil sands development site were outside the $25 \%$ CES being larger than the reference site means. Although within reference site variability in 2012, GSIs were still higher within the oil sands development sites relative to upstream reference. In 2013, all female GSIs fell within reference ranges with no influence of the formation or development. 


\section{SUMMARY}

As a measure of exposure, EROD activity in male white sucker collected within the formation and downstream of oil sands development demonstrated very similar trends between the three years of baseline collections. However, fish EEM health responses varied between years, with male white sucker downstream of oil sands development generally showing most responses (Table 1) in 2011 and 2012. In 2011, males from the site within the formation upstream of oil sands development were similar to fish collected downstream of oil sands development. In 2012, they were intermediate between upstream reference and downstream oil sands development fish. Male fish from all sites in 2013 were similar, demonstrating potential improvements in fish health within the formation and downstream of oil sands development in 2013. Reproductive indicators of gonadosomatic index, circulating steroid levels and expression of secondary sexual characteristics were not consistently altered in male fish within the formation or downstream of oil sands development compared to upstream reference fish outside of the oil sands formation.

Female white sucker demonstrated very similar responses to those of the male white sucker. Exposure appeared to be similar year to year (EROD levels - Table 3) however, fish health responses varied between years with female white sucker downstream of oil sands development generally showing most responses (Table 4). In 2011 and 2012, female white sucker within the formation upstream of oil sands development appeared intermediate to the responses downstream of oil sands development. In 2013, females from all sites were similar, demonstrating potential improvements in fish health within the formation and downstream of oil sands development, greater in females than in males (Table 4). Although not always significantly different, female white sucker downstream of oil sands development generally had larger gonadosomatic indices and larger numbers of eggs. Circulating steroid levels showed no influence of oil sands development and were lower in females collected downstream of the pulp mill discharge in 2013.

\section{DISCUSSION}

Fish monitoring for the EEM program consists of an adult fish population survey and tissue analyses to determine if mill or mine effluent is having an effect on fish and fisheries resources $[5,15]$. The adult fish survey was designed to provide an assessment of whether effluent exposure from a discharge alters growth, reproduction, condition or survival of the selected sentinel fish species. In other terms, estimates of the age or size distribution of the fish population and how well the fish use energy to grow and reproduce and how much energy they store is used to assess impacts of the effluents. These fish response patterns were first used to describe responses to exploitation, recruitment failure, the presence of multiple stressors, food limitation and niche shifts [1]. Identical methods were used in this study to evaluate whether exposure to the oil sands formation itself altered fish health and whether increased exposure due to industrial oil sands activity increased responses relative to upstream reference fish populations [2]. Although oil sands activity has occurred for many years prior to these studies in this area, we refer to these collections as baseline fish health as fish health had not been documented previously in this area and expansion of the oil sands mining continues.

Overall, similar to national evaluations of pulp and paper and metal mining data, white sucker were sensitive sentinel indicators of fish health in this system. Consistent changes in fish health; increased growth, increased condition and increased internal fat stores, were documented within the oil sands formation in 2011 and 2012. These differences were indicative of nutrient enrichment, where fish have more food, so grow faster and store more energy $[1,17]$. A confounding influence in the area is the city of Fort McMurray's municipal waste 
water discharge that is upstream of the AR DS M3 fishing location within the oil sands formation. Nutrient enrichment at this site was intermediate however, with the strongest nutrient enrichment response always seen in fish within the oil sands formation downstream of oil sands development. Fish responses were confirmed in white sucker in the first two years of the studies similar to comparisons made in Canada's EEM programs [5, 15 - presented in 9]. Patterns of nutrient enrichment have also been found in fish downstream of some other municipal sewage discharges and pulp and paper effluent discharges in Canada especially prevalent in receivers that are nutrient poor [19]. In 2013, the third year of baseline fish health collection failed to identify similar differences in white sucker health. Examination of the responses generally showed improvements in condition of the fish (exposed fish more like the upstream reference) [9], and improvements in excessive fat deposits in the body cavity were evident. Lower statistical power in these comparisons requires the confirmation of these responses during the next sampling period. Arens et al. [13] collected spawning white sucker from the Muskeg River, a tributary of the Athabasca River very close to the AR DS M4 location, and also demonstrated increased energy storage in terms of condition factor and liver size relative to fish collected from a lake upstream of the oil sands deposit. Arciszewski et al. [20] re-analysed a long term data set from the Athabasca River (1987-2014) examining fish communities during the spring, summer and fall [6]. Increases in lengths of white sucker and walleye and their relative abundances were found during the spring spawning season. These differences were not observed in surveys conducted in the summer and early fall suggesting that differences in the spring may have been due to reduced fishing pressure in Lake Athabasca where larger fish migrate into the Athabasca River and its tributaries to spawn in the spring [20]. The JOSM fish health program has moved from three intensive years of baseline data collection to a once every three year, long-term monitoring program. It is recommended to evaluate whether improvements in fish health (condition) identified in year three are confirmed in the next sampling period with hopes of larger sample sizes improving the power to detect change.

Reproductive endpoints were fairly consistent in white sucker collected within the Athabasca River over the three years of baseline collections with no confirmed site differences. The EEM program in Canada for pulp and paper and metal mining uses the gonadosomatic index as an endpoint for estimating the energy the fish invests for use in the next reproductive season. Initial studies in Canada found white sucker exposed to pulp and paper mill effluent had reduced gonadal development that corresponded to increased hepatic MFO activity (measure of exposure), reduced circulating levels of reproductive steroids, reduced expression of secondary sexual characteristics and increased age to sexual maturation [10]. These reproductive effects were later correlated to the reduced ability of the ovarian follicles to produce these steroid hormones in vitro [21]. Following multiple cycles of the EEM program for pulp and paper in Canada, national assessments of the data indicated a national response pattern of increased growth of fish, increased condition, increased liver size, increased age but a reduction in investment to gonad size [22] similar to the initial Jackfish Bay study location. It was also found however, that these responses could be masked in some receivers low in nutrients [19] where fish demonstrated more of a nutrient enrichment response pattern. Gonadosomatic indices in this study were fairly consistent between sites and no consistent changes in circulating steroid levels were found confirming a lack of consistent reproductive impact. Steroid levels were somewhat variable but should not have been a result of stress as protocols were followed to reduce the impact of stress on circulating steroid levels [23]. Fecundity or the total number of eggs in the females were sometimes higher downstream of the oil sands development but as fish were also bigger, when expressed relative to length or 
weight, no site differences were present. Fecundity is also a supporting reproductive endpoint in the EEM programs $[5,15]$ however, one needs to be careful and understand the reproductive strategy of their sentinel species when interpreting fecundity estimates [5]. Arens et al. [13] did find reduced gonadosomatic indices in white sucker collected during the spring spawning season from the Muskeg River relative to a reference lake population which they suggested most likely resulted from exposure to polycyclic aromatic hydrocarbons. Tetreault et al. [7] demonstrated reductions in gonadal development and reductions in the in vitro production of reproductive steroids in the Slimy sculpin (a small bodied fish) collected within a tributary running through the same deposit in the Athabasca drainage. These changes were confirmed in a second year of study, however consistent changes in gonadal development were not found in more recent collections [14].

In the EEM programs for pulp and paper and metal mining, it is important to demonstrate exposure especially when there are no differences among sites in fish health endpoints $[5,15]$. Hepatic EROD activity [16] indicates exposure to PACs and related compounds over short time periods [5], and in these studies did indicate exposure of fish to PAC-related compounds both in the formation with some increased exposure downstream of oil sands development. This was also reflected in PAC levels in white sucker liver tissue in both males and females collected in 2013 with increased PACs downstream of oil sands development [14]. Bessonneau et al. [24] used solid-phase microextraction techniques in the induced fish in 2013 to observe significant changes in the levels of anti-oxidants, short-lived oxysterols and other lipids in exposed fish further supporting exposure of white sucker in this system. They however, utilized a much smaller sample size and separated fish based on fold EROD induction; fish with higher EROD induction demonstrated larger changes than fish with lower EROD induction. White sucker were also captured during the fall recrudescent period of development in this study. Doherty et al. [8] document fish movement to be negligible during this stage of development relative to the spawning season when fish may swim long distances to reach spawning areas. Although fish health endpoints recovered somewhat in 2013, this was not evident in levels of induction in either male or female white sucker livers suggesting that exposure levels did not change [9]. Ohiozebau et al. [25] also identified increased concentrations of PAHs in the bile of fish collected from Fort McKay which is closest to the Muskeg AR DS M4 site in these studies. Arens et al. [13] also found induced hepatic EROD activity in spawning white sucker collected from the Muskeg River compared to spawning fish collected from an upstream Calling Lake population. Similar fish health studies conducted on a tributary to the Athabasca River, the Steepbank River also demonstrated induced EROD activity in Slimy sculpin (Cottus cognatus) collected downstream of oil sands development [7] and increased whole body PACs [14]. Parrott et al. [26] more recently identified increased levels of PAHs and alkylated PAHs in snow collected on that and other tributaries in the development area of the oil sands. When exposed to fathead minnow embryos, increased mortality resulted. Although abnormalities were recorded during the collections of the white sucker from these studies, no increased levels of deformities were identified within the deposit or downstream of development [14]. Hogan et al. [27] measured CYP1A in livers of yellow perch held in oil sands-affected waters in two experimental ponds and found that its activity correlated positively with the incidence of disease pathologies over long term exposures. Concentrations of naphthenic acids and PAHs however, would be higher in these ponds than in the Athabasca River itself.

The increased condition of fish within the deposit downstream of development activity exceeded defined critical effects sizes established in the Canadian EEM programs [4, 5 document in 9]. We conducted similar evaluations of upstream reference site variability in 
gonadal development using the five reference site collections from the three years of study for both male and female white sucker. In the EEM programs these CESs are used to manage the program and determine what should be done in the next cycle of monitoring $[5,15]$. For instance, if effects are confirmed and are outside of the CES set within the program, focused studies are triggered looking at the magnitude and extent of the changes. If the effects exceed CES and are getting worse, investigation of cause and investigation of solutions follow in the program [5, 15]. In this case, male gonadosomatic indices for the furthest upstream reference site in 2013 approach the overall CES, clearly increases this overall range. Temperature data from these sites need to be evaluated to help understand this reference site variability and to help predict potential change into the future. Additional tools are being developed to assess change within and between sites within the oil sands area. With three years of data at individual sites, normal can be defined for that site over the three years of monitoring. To do this, a cumulative mean \pm 2 SD is calculated and then used to make more meaningful predictions of future observations as more data are added [28]. These tools should be used to make predictions of fish health into the future and to identify change within site and between sites in the oil sands area that are meaningful.

\section{ACKNOWLEDGEMENTS}

The authors would like to thank all who participated in fish health collections and lab work over several years: Mark Hewitt, Adrienne Bartlett, Dominique Turcotte, Alicia Mehlenbacher, Ross Neureuther, Christine Lavalle, Richard Frank, Nicholas Maya, Kazlyn Bonnor, Jennifer Ings, Deanna Murray, Katherine French, Lana Miller, Anthony Bauer, Shannon McFadden, Jonathon Keating, Kallie Shires, Meghan Bree, Michael Dunning, Mandeep Mann, Ola Oni, Tannis Neheli, Sorina Chiorean and Daniel Byrne. Thank you to Hatfield Consultants for their collaborative efforts and great assistance helping work in such difficult environments.

\section{FUNDING}

This study was supported by funds provided by Environment and Climate Change Canada and the Joint Oil Sands Monitoring Program.

\section{REFERENCES}

[1] Munkittrick, K.R. \& Dixon, K.G. A holistic approach to ecosystem health using assessment of fish population characteristics. Hydrobiologia, 188/189, pp. 123-135, 1989.

[2] Environment Canada (2011) Integrated Monitoring Plan for the Oil Sands - Expanded Geographic Extent for Water Quality and Quantity, Aquatic Biodiversity and Effects, and Acid Sensitive Lake Component (En14-49/2011E-PDF ISBN 978-1-100-18939-0).

[3] Environment Canada Joint Oil Sands Monitoring data portal, available at www.jointoilsandsmonitoring.ca/flex/index.html?lang=en.

[4] Culp, J.M., Droppo, I.G., di Cenzo, P.D., Alexander-Trusiak, A., Baird, D.J., Bickerton, G., Beltaos, S., Bonsal, B., Brua, R.B., Chambers, P.A., Dibike, Y., Glozier, N.E., Kirk, J., Levesque, L., McMaster, M., Muir, D., Parrott, J., Peters, D.L., Pippy, K. \& J.W. Roy. 2018. Synthesis report for the water component, Canada-Alberta joint oil sands monitoring: key findings and recommendations. Oil Sands Monitoring Program Technical Report Series No. 1.1. 46 p.

[5] Environment Canada (2010) Pulp and Paper Environmental Effects Monitoring (EEM) Technical Guidance Document. National EEM Office, Environment Canada, Ottawa, Ontario. Online, www.ec.gc.ca/eem/pdf_publications/English/TGD_e.pdf. 
[6] Regional Aquatic Monitoring Program data portal, available at http://www.ramp-alberta.org/RAMP.aspx.

[7] Tetreault, G.R., McMaster, M.E., Dixon, D.G. \& Parrott, J.L. Using reproductive endpoints in small forage fish species to evaluate the effects of Athabasca Oil Sands activities. Environmental Toxicology and Chemistry, 22(11), pp. 2775-2782, 2003.

[8] Doherty, C.A., Curry, R.A. \& Munkittrick, K.R. Spatial and temporal movements of white sucker: implications for use as a sentinel species. Transactions of the American Fisheries Society, 139(6), pp. 1818-1827, 2010.

[9] McMaster, M.E., Tetreault, G.R., Clark, T., Bennett, J., Cunningham, J. \& Evans, M., "Aquatic ecosystem health assessment of the Athabasca River mainstem oil sands area using white sucker health" WIT Transactions on Ecology and the Environment, Vol 21, WIT, 2018, ISSN 174-3541, pp. 411-420.

[10] McMaster et al. Changes in hepatic-mixed function oxygenase (MFO) activity, plasma steroid levels and age at maturity of a white sucker (Catostomus commersoni) population exposed to bleached kraft pulp mill effluent. Aquatic Toxicology, 21:199-218, 1991.

[11] Bowron, L.K. et al. Responses of white sucker (Catostomus commersoni) to 20 years of process and waste treatment changes at a bleached kraft pulp mill, and to mill shutdown. Aquatic Toxicology, 95, pp. 117-132, 2009. Doi:10.1016/jh.aquatox.2009.08.009

[12] Arciszewski, T.A., McMaster, M.E., Portt, C.B. \& Munkittrick, K.R. Detection of food limitation in health of white sucker (Catostomus commersoni) 5 years after the closure of a bleached kraft pulp mill. Water Quality Research Journal of Canada, 50(2), pp. 152-166. Doi.org/10.2166/wqrjc.2014.130

[13] Arens, C.J., et al. Population impacts in white sucker (Catostomus commersoni) exposed to oil sands-derived contaminants in the Athabasca river. Environmental Toxicology and Chemistry, 36(8), pp. 2058-2067, 2017. DOI: 10.1002/etc.3735

[14] McMaster et al. Aquatic ecosystem health assessment of the Athabasca River mainstem and tributaries using fish health and fish and invertebrate toxicological testing. Oil Sands Monitoring Program Technical Report Series No. 1.8, pp. 76.

[15] Environment Canada (2012) Metal Mining Technical Guidance for Environmental Effects Monitoring. National EEM Office, Environment Canada, Ottawa, Ontario, available at www.ec.gc.ca/esee-eem/default.asp?lang=En\&n=AEC7C481-1.

[16] Van den Heuvel, M.R., Munkittrick, K.R., Stegeman, J.J. \& Dixon, D.G. Second-round interlaboratory comparison of hepatic ethoxyresorufin-O-deethylase activity in white sucker (Catostomus commersoni) exposed to bleached-kraft pulp mill effluent. Environmental Toxicology and Chemistry, 14(9), pp. 1513-1520, 1995.

[17] Munkittrick, K.R. \& Dixon, D.G. Growth, fecundity, and energy stores of white sucker (Catostomus commersoni) from lakes containing elevated levels of copper and zinc. Canadian Journal of Fisheries and Aquatic Sciences, 45, pp. 1355-1365, 1988.

[18] McMaster, M.E., Munkittrick, K.R., \& Van Der Kraak, G.J. Protocol for Measuring Circulating Levels of Gonadal Sex Steroids in Fish. Canadian Technical Report of Fisheries and Aquatic Sciences 1836. Department of Fisheries and Oceans, Burlington, ON, Canada, 1992.

[19] McMaster et al. Detailed endocrine assessments of wild fish in the Northern River Basins, Alberta, in comparison to EEM monitored endpoints. Water Quality Research Journal of Canada, 40(3), pp. 299-314, 2005. 
[20] Arciszewski, T.J., Munkittrick, K.R., Kilgour, B.W., Keith, H.M., Linehan, J.E. \& McMaster, M.E. Increased size and relative abundance of migratory fishes observed near the Athabasca oil sands. Facets, 2, pp. 833-858, 2017. DOI: 10.1139/facets-2017-0028

[21] McMaster, M.E., Van Der Kraak, G.J., \& Munkittrick, K.R. Exposure to bleached kraft pulp mill effluent reduces the steroid biosynthetic capacity of white sucker ovarian follicles. Comparative Biochemistry and Physiology, 112(C) pp. 169-178, 1995.

[22] Munkittrick, K.R., McMaster, M.E., \& Servos, M.R. Detection of reproductive impacts of effluents from pulp and paper mills: shifts in issues and potential causes. Environmental Toxicology and Chemistry, 32(4), pp. 729-731, 2013. Doi:10.1002/etc.2143

[23] McMaster, M.E., Munkittrick, K.R., Luxon, P.L., \& Van Der Kraak, G.J. Impact of low-level sampling stress on interpretation of physiological responses of white sucker exposed to effluent from a bleached kraft pulp mill. Ecotoxicology and Environmental Safety, 27, pp. 251-264, 1994.

[24] Bessonneau, V., Ings, J., McMaster, M., Smith, R., Bragg, L., Servos, M., \& Pawliszyn, J. In vivo tissue sampling using solid-phase microextraction for non-lethal exposomewide association study of CYP1A1 induction in Catostomus commersoni. Environmental Research, 151, pp. 216-223, 2016.

[25] Ohiozebau, E. et al., Products of biotransformation of polycyclic aromatic hydrocarbons in fishes of the Athabasca/Slave river system, Canada. Environmental Geochemistry and Health, 38(2), pp. 577-591, 2015. DOI 10.1007/s10653-015-9744-6

[26] Parrott, J.L. et al. Meltwater from snow contaminated by oil sands emissions is toxic to larval fish, but not spring river water. Science of the Total Environment, 625 pp. 264-274, 2017. Doi.org/10.1016/j.scitotenv.2017.12.284

[27] Hogan, N.S., Thorpe, K.L., \& van den Heuvel, M.R. Opportunistic disease in yellow perch in response to decadal changes in the chemistry of oil sands-affected waters. Environmental Pollution, 234, pp. 769-778, 2018.

[28] Arciszewski, T.J. \& Munkittrick, K.R. Development of an adaptive monitoring framework for long-term programs: an example using indicators in fish. Integrated Environmental Assessment and Management, 11(4), pp. 701-718, 2015. DOI:10.1002/ ieam.1636 